Feelings of inferiority: A first attempt to define the construct empirically

By: Katie A. Lamberson and Kelly L. Wester

Lamberson, K. A., \& Wester, K. L. (2018). Feelings of inferiority: A first attempt to define the construct empirically. Journal of Individual Psychology, 74(2), 172-187.

Made available courtesy of University of Texas Press: http://doi.org/10.1353/iip.2018.0011

This is a pre-copyedited version of an article accepted for publication in Journal of Individual Psychology following peer review. The definitive publisher-authenticated version is available through the University of Texas Press.

$* * *$ (C) 2018 University of Texas Press. Reprinted with permission. No further reproduction is authorized without written permission from University of Texas Press. This version of the document is not the version of record. Figures and/or pictures may be missing from this format of the document. ***

\begin{abstract}
:
Inferiority feelings have been linked theoretically to substance use; however, an empirical definition of the construct is lacking in research. The purpose of this study was to examine the adequacy in defining inferiority feelings using the empirically established constructs of selfesteem, general self-efficacy (GSE), abstinence self-efficacy (ASE), and shame using a sample of 210 undergraduate college students. Results of the confirmatory factor analysis indicated that the overall model provided good fit for the data; however, self-esteem and shame loaded more strongly on the latent construct than did GSE and ASE. The results provide preliminary evidence for using these constructs to define inferiority feelings; however, future research is necessary to examine alternate constructs that may define inferiority feelings in other populations.
\end{abstract}

Keywords: inferiority | self-efficacy | self-esteem | shame | substance use

\title{
Article:
}

Substance use is a prevalent concern in today's society, specifically amongst young adults aged $18-25$. According to the National Survey of Drug Use and Health, approximately $58.3 \%$ of individuals in this age group report use of alcohol, and $22.3 \%$ report use of illicit drugs (Center for Behavioral Health Statistics and Quality, 2016). Furthermore, substance-use disorders (SUDs) are the most common diagnosis among this emerging-adult population (Davis \& Vander Stoep, 1997), and individuals in this age group demonstrate higher rates of SUDs than do other age groups (National Institute on Drug Abuse, 2014; Pottick, Warner, Stoep, \& Knight, 2014). This reality highlights the importance of understanding potential contributing factors to the rates of substance use within this vulnerable population.

Alfred Adler conceptualized substance use as a form of neurosis (Abramson, 2015; BartonBellessa, Lee, \& Shon, 2015) that results from an individual's inability to cope with the life tasks 
of work, love, friendship, spirituality, and self (Dreikurs, 1990; Steffenhagen, 1974) in socially acceptable ways. In theory, this maladaptive method of navigating life tasks often results from an individual's feelings of inferiority. This idea serves as the theoretical basis for the study, yet it has not been explored empirically.

An individual's social environment is important to consider (Sweeney, 2009) when examining feelings of inferiority, as the feelings can result from negative social comparisons (Appel, Crusius, \& Gerlach, 2015). Individuals recognize from a young age their own deficiencies and dependence on others (Barton-Bellessa et al., 2015). This recognition leads to the need to "strive for superiority," by which individuals create ambitions for themselves that when not met may lead to feelings of inferiority (Abramson, 2015). This idea is supported, as both depressive symptoms and envy are positively correlated with feelings of inferiority, whereas envy is also negatively correlated with self-esteem (Appel et al., 2015). Although Appel et al. (2015) provided an example of constructs that are related to feelings of inferiority, they did not define what constitutes feelings of inferiority outside of reported happiness as compared to others. A further review of the literature provides a rationale for examining self-esteem, shame, general self-efficacy (GSE) and abstinence self-efficacy (ASE) as potential measureable constructs that may be appropriate in defining inferiority feelings in individuals with SUDs.

\section{Feelings of Inferiority}

\section{Adler's View of Inferiority Feelings}

Adler described feelings of inferiority as subjective evaluations that are both normal and motivating. Because children are born into an environment of adults, they are viewed as smaller and weaker, which creates a universal sense of inferiority among all humans that is subjectively based on perception rather than in reality (Adler, 1956; Mosak \& Maniacci, 1999). These feelings, however, can motivate individuals to strive toward higher positions, or superiority, as individuals begin to interact with their social environment and realize how they fit among other individuals. Thus, inferiority feelings can prove positive as individuals use them as a motivating factor toward reaching their goals (Adler, 1956).

Inferiority feelings can manifest as abnormal when individuals do not use them as inspiration to achieve success. These individuals, often afflicted with organ inferiority, may lack social interest. Individuals who do not view their inferiority in the context of others, but rather from a selfish standpoint, may be more driven by fear of failure than by movement toward success. This selfishness, according to Adler (1956), is often a result of pampering, which in his view hinders the child from developing social interest.

Adler related his view of inferiority feelings to substance use by highlighting that those who struggle with addiction demonstrate strong feelings of inferiority. These individuals, rather than experience these feelings, use substances to displace responsibility from the individual to the substance. In other words, rather than admit to flaws that place individuals in a lower social position, individuals who use substances can blame their use for these flaws (Adler, 1956).

Contemporary Views of Inferiority Feelings 
Over the years, feelings of inferiority have been defined by a number of separate but related constructs, such as failure, worthlessness, a low sense of belonging, questioning of competence, low self-esteem, envy, depressive symptoms, self-doubt, and feelings of not being accepted by society (Abramson, 2015; Appel et al., 2015; Dreikurs, 1990); however, no empirical research exists to substantiate these theoretical conceptualizations (Gupta, 1996). This lack of empirical evidence may be related to difficulty in defining the concept due to the multiple constructs that likely constitute it (Strano \& Dixon, 1990). Although some differences exist in theoretical definitions, researchers seem to agree that feelings of inferiority are important in understanding adjustment issues and maladaptive coping strategies, such as SUDs (Barton-Bellessa et al., 2015; Dreikurs, 1990; Gupta, 1996), a fact that highlights the overall importance of determining an empirical definition that can provide insight into addressing these adjustment issues more accurately. The constructs being used to define feelings of inferiority in this study are grounded in existing literature (outlined below). Therefore, because feelings of inferiority are important theoretically, and have specifically been stated to be an underlying component of substance use (Abramson, 2015), determining an empirical definition is imperative for better understanding of how feelings of inferiority play a practical role in individuals who use substances.

\section{Self-Esteem}

Self-esteem, defined as a positive or negative belief about the self as worthy or unworthy (Baumeister, 1998; Rosenberg, 1965), has been identified as one component that defines feelings of inferiority (Dreikurs, 1990; Strano \& Dixon, 1990). An incongruence between who one believes himself to be (self-concept) and who one believes he should be (self-ideal) can lead to feelings of low self-esteem that manifest in thoughts related to one's worth (Alexander, 1938; Mosak \& Maniacci, 1999). This incongruence often results from social comparisons that affect feelings of inferiority, and those who view themselves as less than often have low selfesteem. Individuals who experience feelings of inadequacy may search for a solution to these feelings (Abramson, 2015), which may lead to substance use as a method of avoiding negative feelings or of creating synthetic feelings of adequacy and worth. The use of substances as a coping mechanism can further increase feelings of inferiority by increasing subsequent feelings of envy toward those who do not utilize substances to cope (Appel et al., 2015) or shame with oneself for doing so (Alexander, 1938). This demonstrates that self-esteem may only partially describe the overarching concept of feelings of inferiority, as shame may also play a role.

\section{Shame}

Feelings of inferiority include those of not being accepted by others (Dreikurs, 1990) and having a low sense of belongingness (Abramson, 2015). Similarly, shame is often linked in the literature to feelings of rejection (Gausel, Leach, Vignoles, \& Brown, 2012). Feelings of rejection are found to be associated with lower self-esteem (Gausel et al., 2012). Like self-esteem, shame is often experienced as a result of incongruence between the self-concept and the self-ideal (Tangey \& Dearing, 2002), which has been shown to decrease self-efficacy by increasing feelings of incompetence (del Rosario \& White, 2006). Shame is described as an enduring, chronic sense of inferiority, inadequacy, or deficiency that has become internalized as part of one's identity (Tangey \& Dearing, 2002), a conceptualization that emphasizes the trait-based 
nature of the construct. However, shame has been conceptualized as both a state and a trait variable. Because of the stable way in which Adler described feelings of inferiority, trait-like conceptualizations of shame may be more closely aligned with the construct of feelings of inferiority.

Individuals identified as having substance-use problems are found to have higher levels of shame than individuals with other mental health problems and the general population (O'Connor, Berry, Inaba, Weiss, \& Morrison, 1994). Individuals who experience these strong, negative evaluations about the self may use substances as an escape from the pain of their feelings (Adler, 2005; Cook, 1988) but, in turn, may experience increased feelings of shame with themselves for doing so (Cook, 1988; Wiechelt, 2007). This under scores the reciprocal relationship between shame and substance use. The relationship between shame and substance use is evidenced conceptually in the literature; however, there is scarce empirical evidence evaluating these relationships (McGaffin, Lyons, \& Deane, 2013).

\section{General Self-Efficacy (GSE)}

According to Adlerian theory, feelings of inferiority may result when an individual questions his or her abilities (Dreikurs, 1990). Self-efficacy is a cognitive process that describes an individual's confidence in performing a specific ability (Bandura, 1977). In contrast, GSE is defined as an individual's perception of his or her ability to perform across a variety of situations (Judge, Erez, \& Bono, 1998). In other words, although self-efficacy is a situation-specific belief in one's competence, GSE is a traitlike belief in one's overall competence (Scherbaum, CohenCharash, \& Kern, 2006). Although task-specific self-efficacy and GSE are distinct constructs, as is evident by their distinct relationships with self-esteem (Judge et al., 1998), they are related (Sherer et al., 1982). This suggests a potential relationship between GSE, task-specific selfefficacy, and self-esteem with inferiority feelings.

\section{Abstinence Self-Efficacy (ASE)}

Because inferiority feelings have been defined as questioning one's abilities (Dreikurs, 1990) and self-efficacy was initially conceptualized as a task-specific construct (Bandura, 1977), it is important to consider self-efficacy as it relates to substance use when considering inferiority feelings in individuals who cope with use of substances. ASE is a task-specific self-efficacy that describes confidence in the ability to remain abstinent from substances in high-risk situations. Low ASE is positively related to relapse in that when an individual is successful at maintaining abstinence in a high-risk situation, ASE will increase and the individual will have increased confidence to remain abstinent in future situations (Marlatt, 1985). Furthermore, ASE is found to be predictive of treatment efficacy (DiClemente, Carbonari, Montgomery, \& Hughes, 1994), thus emphasizing the importance of considering self-efficacy when providing treatment for SUDs. For example, in a study of adolescent substances users, higher ASE was predictive of lower drug use during treatment (Burleson \& Kaminer, 2005). Similarly, ASE increased during treatment for use of crack cocaine, with clients reporting abstinence 1 month after treatment also reporting higher levels of ASE (Coon, Pena, \& Illich, 1998). This highlights the positive impact of treatment on ASE and the reciprocal relationship between ASE and abstinence. Thus, it may be 
true that as individuals compare their own high ASE to others in treatment, their feelings of inferiority decrease.

As noted throughout, a review of relevant literature provides an argument for exploring the appropriateness of defining feelings of inferiority, specifically as they relate to SUDs, using the constructs self-esteem, GSE, ASE, and shame. Despite theoretical similarities, each of these constructs remains distinct, offering an argument for including each one to empirically define the larger concept of feelings of inferiority. Empirical understanding of each of the unique constructs that constitute feelings of inferiority can positively affect clinical treatment of SUDs, as practitioners can focus on each individual factor that may be influencing the use of substances. Although Adler's concept of inferiority is theoretically known and understood to lead to substance use, no empirical research exists to operationally define this construct. Therefore, the purpose of this study is to answer the following research question: Do the observed constructs of self-esteem, GSE, ASE, and shame measure the latent construct of inferiority feelings in individuals reporting use of alcohol and or drugs?

\section{Methods}

\section{Participants}

The sample consisted of 210 undergraduate college students recruited from a midsize public university in the southeastern United States. Participant ages ranged from 18 to $25(M=$ $20.7, S D=1.58)$. The majority of the sample consisted of women $(n=151,71.9 \%)$, with $26.7 \%$ men $(n=56)$, and $1.4 \%(n=3)$ not indicating gender. Ninety-two participants $(43.8 \%)$ from the sample identified as White, $77(36.7 \%)$ identified as Black, $16(7.6 \%)$ as multiracial, $10(4.8 \%)$ as Asian, 9 (4.3\%) as Hispanic, 5 (2.4\%) self-selected "Other," and 1 (.5\%) did not report on race/ethnicity.

Participants were also asked a variety of questions related to their overall experiences with alcohol and drugs. Drinking alcohol was more common among participants than using drugs. While 28 participants $(13.3 \%)$ reported never having taken a drink of alcohol (beyond just one sip) and 1 participant (.5\%) did not identify the age of first drink, the majority of participants $(n=182,86.6 \%)$ did report using substances. Most participants indicated having a first drink of alcohol between the ages of 16 and $23(n=147,70.3 \%)$, and the remainder of participants $(n=$ $34,16.3 \%$ ) reported having their first drink between ages 10 and 15 . Approximately $76.1 \%$ reported that their first drink of alcohol was before the legal drinking age of 21 . When separately asked about drug use, more than half of participants $(n=129,61.4 \%)$ denied ever taking drugs, with $38.6 \%$ indicating some drug use. The age of first drug use for the remainder of participants ranged from 12 to $20(n=81,38.5 \%)$. Most participants $(n=189,90 \%)$ reported having peers who use alcohol or drugs, and slightly more than half $(n=110,52.4 \%)$ indicated a family history of drug or alcohol abuse. Finally, although $21 \%$ of participants indicated clinically significant alcohol use and 7\% indicated clinically significant drug use, 206 participants $(98.1 \%)$ denied any current or previous participation in treatment services addressing any concerns related to drug or alcohol use.

Procedures 
Given the higher rates of use and diagnosis of substance use among emerging adults in college, for this study we utilized convenience sampling to access undergraduate students between the ages of 18 and 25. After obtaining approval from the university's institutional review board, participants were recruited from nine undergraduate courses in two departments on campus. Each participant was provided information (oral and written) explaining the nature of the study and provided informed consent. Because of the sensitive nature of the study, we were granted a waiver of signed informed consent to further protect participants' confidentiality. Students willing to participate completed the survey packet, which took 20-35 minutes. Participants were provided with a list of substance-use resources following completion of the study and had the option to enter a drawing to win one of eight $\$ 10$ gift cards as an incentive to participate.

\section{Measures}

Self-esteem. Self-esteem was measured using the Rosenberg Self-Esteem Scale (RSES; Rosenberg, 1965). The RSES is a 10-item self-report instrument that measures selfesteem as a unidimensional construct on a continuum from low to high (Rosenberg, 1965). Respondents answer each question on a 4-point Likert scale ( $1=$ strongly agree, $4=$ strongly disagree). The RSES has been utilized with a variety of populations and is one of the most widely accepted measures of self-esteem (Heatherton \& Wyland, 2003). The RSES has moderate to high test-retest reliability $(r=.85)$ and internal consistency $(\alpha=.92$; Heatherton $\&$ Wyland, 2003; Rosenberg, 1965). The RSES was correlated with other constructs that have been theoretically associated with self-esteem (e.g., depression, anxiety) to establish construct validity (see Table 1).

Table 1. Descriptive Statistics and Reliability Estimates of Scales

\begin{tabular}{|lcccc|}
\hline Instruments and Subscales & $\boldsymbol{M}(\boldsymbol{S D})$ & Possible/Observed Range & Number of Items & Alpha Coefficient \\
\hline RSES & $32.26(5.39)$ & $1-4$ & 10 & 0.89 \\
NGSE & $34.66(4.44)$ & $1-5$ & 8 & 0.92 \\
AASE-Temptation & $12.10(4.72)$ & $1-5$ & 6 & 0.82 \\
AASE-Confidence & $24.6(4.98)$ & $1-5$ & 6 & 0.87 \\
ISS & $29.49(20.02)$ & $0-4$ & 24 & 0.96 \\
\hline
\end{tabular}

Note. RSES = Rosenberg Self-Esteem Scale; NGSE = New General Self-Efficacy Scale; AASE-Temptation = Alcohol Abstinence Self-Efficacy Scale, temptation scale; AASE-Confidence = Alcohol Abstinence Self-Efficacy Scale, confidence scale; ISS = Internalized Shame Scale.

General Self-Efficacy (GSE). The New General Self-Efficacy Scale (NGSE; Chen, Gully, \& Eden, 2001) was used to assess GSE. The NGSE is made up of 8 items measured on a 5-point Likert scale ranging from 1 (strongly disagree) to 5 (strongly agree), with higher scores indicating higher levels of GSE (Scherbaum et al., 2006). The NGSE demonstrates adequate reliability estimates across two cultures (Cronbach's $\alpha=.85$ to .91 , test-retest reliability; $r=.62$ to .86; Chen et al., 2001). The NGSE correlated with the RSES and the General Self-Efficacy Scale (SGSE), with results suggesting that GSE and self-esteem are separate but related constructs $\left(\chi^{2}=144.31\right.$; Chen et al., 2001), providing further evidence of discriminant validity (see Table 1).

Abstinence Self-Efficacy (ASE). To assess ASE, the 12-item brief version of the Alcohol Abstinence Self-Efficacy Scale (AASE; McKiernan, Cloud, Patterson, Golder, \& Besel, 2011) 
was used. This brief measure is modeled after the original 40-item AASE, which was created to evaluate self-efficacy in relation to abstinence from alcohol and has been found to be a psychometrically sound method of assessing ASE (DiClemente et al., 1994). The brief 12-item version of the AASE assesses confidence (6 items) and temptation (6 items) on a 5-point Likert scale ranging from 1 (not at all) to 5 (extremely). Total ASE score is calculated by subtracting the temptation score from the confidence score (McKiernan et al., 2011). The brief version of the AASE demonstrated good internal consistency reliability $(\alpha=.916$ for confidence, $\alpha=.878$ for temptation; McKiernan et al., 2011) (see Table 1).

Shame. The Internalized Shame Scale (ISS; Cook, 1988) was used to measure shame. The ISS is a self-report measure that consists of 30 items that measure two subscales: shame (24 items) and self-esteem (6 items) to assess a trait-based measure of shame (del Rosario \& White, 2006). Scores for each subscale are calculated separately, and for the purpose of this study, only the shame subscale was utilized. Questions on the shame subscale are answered on a 4-point Likert scale ranging from 0 (never) to 4 (almost always), with higher scores indicating higher levels of shame (Cook, 1996). The ISS exhibits adequate reliability and validity in both clinical and nonclinical populations, with test-retest reliability ranging from $r=.81$ to .84 , and internal consistency ranging from $\alpha=.95$ to .97 (Cook, 1996; del Rosario \& White, 2006; Rybak \& Brown, 1996). The ISS was correlated with the Multiple Affect Adjective Check List-Revised (MAACL-R) to establish construct validity (anxiety, $r=.69$; depression $r=.72$; hostility, $r=$ .53; positive affect, $r=-.56)$. Finally, the ISS was correlated with other established measures of shame and guilt (e.g., Personal Feelings Questionnaire), with correlations ranging from .39 to .64 , providing indication of concurrent validity (see Table 1 ).

Demographics. Developed for this study, the demographics questionnaire consisted of 12 items exploring participant age, gender, race/ethnicity, age of first alcohol use, age of first drug use, peer substance use, and family history of substance use.

\section{Data Analysis}

Data were entered into SPSS Statistics Version 20 to examine descriptive statistics of the demographic data and assess for internal consistency reliability of the data for the manifest variables. Examination of the histogram distribution for the self-esteem data revealed a negatively skewed distribution. Because one of the key assumptions of confirmatory factor analysis (CFA) is multivariate normality (Kline, 2011), a log 10 transformation was performed on the self-esteem data.

Means, standard deviations, and Cronbach's alpha for each of the scales are reported in Table 1. Because total scores for ASE are calculated by subtracting total temptation score from total confidence score, descriptive statistics and reliability estimates of both AASE scales are reported.

We then entered data into LISREL Version 9.2 and analyzed the research question using CFA to determine the accuracy in defining the latent construct, inferiority feelings, with the manifest variables of self-esteem, GSE, ASE, and shame (see Figure 1). We examined multiple indexes of fit and examination of the chi-square analysis $\left(\chi^{2}=2.67, d f=2, p=0.2682\right)$ indicated a good fit 
of the model to the data. Consistent with chi-square results, examination of root mean square error of approximation (RMSEA) also suggested good fit $(0.04 \leq .05)$. Additionally, standardized root mean square residual $(\mathrm{SRMR})(0.0276 \leq .10)$ and comparative fit index (CFI) $(0.997 \geq$ .90; Kline, 2011) demonstrated good fit for the data. Results of each of the global statistics suggest the model is an excellent fit for the data (Kline, 2011; see Table 2).

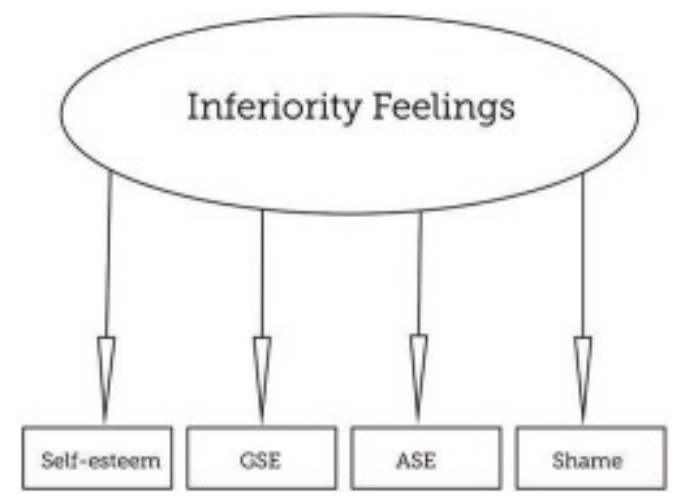

Figure 1. Inferiority Feelings Model.

Table 2. Goodness-of-Fit Indexes for CFA and Structural Regression Model

\begin{tabular}{|lcccccc|}
\hline Hypothesized Model & $\chi^{2}$ & $d f$ & $p$ value & RMSEA & SRMR & CFI \\
Inferiority feelings & 2.67 & 2 & 0.2682 & 0.04 & 0.0276 & 0.997 \\
\hline
\end{tabular}

Note. RMSEA = root mean square error of approximation; SRMR = standardized root mean square residual; CFI = comparative fit index.

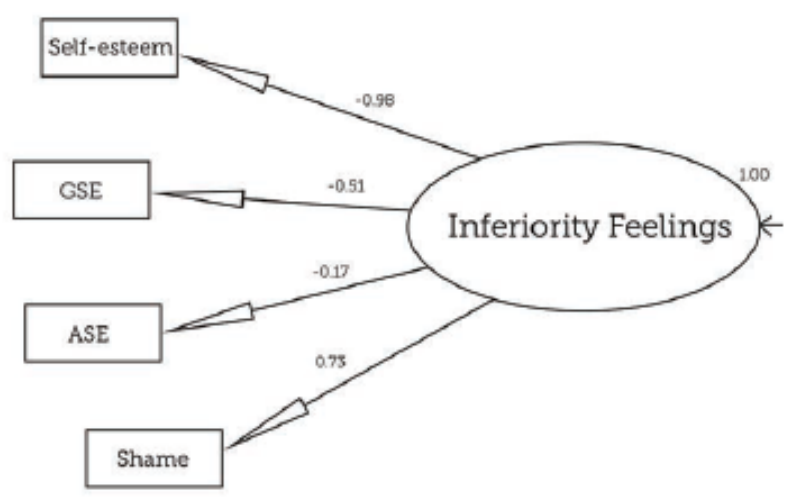

Figure 2. Inferiority Feelings Model With Standardized Factor Loadings.

The factor loadings for the standardized solution (see Figure 2) in the CFA suggest that selfesteem (-0.98) and shame (.73) may explain the latent construct inferiority feelings; however, because factor loadings for GSE and ASE are less than the desired $\geq .70(-.51$ and -.17 , respectively), and the measurement errors are above the desired $\leq .50$ (.74 and .97 , respectively), more than half of the variance for each of these variables is explained by other factors or measurement error (Kline, 2011).

\section{Results}


Results of the CFA supported the observed constructs as a measurable definition of inferiority feelings, as the overall model provided an excellent fit for the data. These results provide an argument for the use of self-esteem, GSE, ASE, and shame to measure feelings of inferiority in future research. Despite this, the data suggest that self-esteem and shame appear to have a strong relationship to the construct of inferiority feelings, whereas ASE and GSE do not. The poor factor loadings related to GSE and ASE indicate that additional research is necessary to examine constructs that are not task-specific, as inferiority feelings can exist in individuals not experiencing problematic substance use.

\section{Discussion}

The goal of this study was to identify an empirical definition of the Adlerian construct of inferiority feelings. Adler wrote about inferiority as a continuum with superiority on one end and inferiority on the other. In the current study, it appears that the observed constructs measure this continuum. In the current study, self-esteem, GSE, and ASE were all negatively related to the latent construct, suggesting that the more self-esteem, GSE, and ASE individuals perceive in themselves, the more positive evaluations and feelings they hold about the self, or the lower the feelings of inferiority. Similarly, shame was positively related to the construct, signifying that higher levels of shame are inversely related to superiority feelings and, as a consequence, more feelings of inferiority.

Despite the overall fit of the model, only self-esteem and shame were found to load strongly onto the construct inferiority feelings, whereas GSE and ASE revealed factor loadings that suggest that more than $50 \%$ of the variance may be accounted for by factors outside of the model. Selfesteem and shame have previously been linked to substance use in research (Donnelly, Young, Pearson, Penhollow, \& Hernandez, 2008; Tangey \& Dearing, 2002); however, little research exists examining the relationship between GSE and SUDs, as GSE is a measure of overall feelings of self-efficacy. Additionally, although ASE has been associated with decreased relapse (Marlatt, 1985) and better treatment outcomes (DiClemente et al., 1994), the relationship between ASE and SUDs has not previously been explored in a nonclinical sample. In the current sample, mean ASE scores were high, which may be due to the low rates of individuals reporting substance use treatment $(<1 \%, n=4)$. The low rates of treatment reported in the current sample may suggest that participants may not consider their substance use as problematic, and thus do not see a need to maintain abstinence. Given the overall fit of the model, further research is necessary to examine how well these variables load in other populations. Although GSE was only marginally related to the latent construct, the general nature of the construct and its previous correlation with self-esteem and shame suggest that it may be worth continuing to explore in other populations. These results are noteworthy, as each construct has been identified as having potential infiuence on individual outcomes, yet this is the first empirical investigation of these constructs that has been appropriate for measuring the latent construct of inferiority. Overall, the results of this study support Adler's original theory of inferiority.

\section{Limitations}

Several limitations are noted with regard to the current study. Data for the current study were collected from one midsize university in the southeastern United States, which restricts 
generalizability of the findings to other populations. Furthermore, the length of the survey is extensive, which may have deterred eligible participants from participating in the survey or may have increased fatigue while responding to survey items. Last, although the brief version of the AASE has been found to be a valid and reliable instrument (McKiernan et al., 2011), it has had limited use in empirical research and was initially normed on a clinical population. Although the utility of this instrument in exploring ASE in a nonclinical college population had not been examined before this study, the internal consistency of each scale ( $\alpha=.87$ for confidence; $\alpha=.82$ for temptation) revealed that the AASE may be a reliable instrument when used with such a population. Further empirical exploration of the brief version of the AASE is necessary to confirm the utilization of this instrument in nonclinical, college-aged populations.

\section{Implications}

The measurable constructs of self-esteem, GSE, ASE, and shame may adequately define the theoretical continuum of superiority and inferiority feelings, particularly as they relate to SUDs (due to the inclusion of the task-specific variable of ASE). Researchers who wish to examine internalizing experiences of the individual may benefit from this knowledge as it provides insight into how each of these constructs is related and plays a role in an individual's self-evaluations. Generally speaking, because the measurable constructs are found to be related to the larger construct of inferiority, it is possible that examining these constructs separately may not provide a comprehensive understanding of the way in which an individual views himself and may impact other factors. Yet the poor factor loadings of the variables GSE and ASE on inferiority feelings implies a need to further explore potential variables that may define the latent construct. Specifically, inferiority feelings may exist in individuals who do not use substances; thus, constructs that are not task-specific, such as ASE, may be worth exploring in defining the latent variable. The existence of empirical definitions for the Adlerian constructs of inferiority feelings can assist in infusing theory and research by allowing for empirically validated incorporation of theoretical constructs into research.

Findings from the current study have a particular impact on practitioners, specifically Adlerians. Better understanding of the constructs that make up inferiority feelings can allow practitioners to address each of these constructs, providing a more holistic picture of an individual's evaluations of the self. Comprehensive understanding of these evaluations can improve the effectiveness of treatment by addressing beliefs about the self as worthy, perceptions of competence, as well as internalized feelings of inadequacy and how they each may relate to individual outcomes. In the case of SUDs, understanding and treating each of these internal thoughts and feelings, as well as working on abstinence self-efficacy, can increase long-term results, as each may play a role in the use of substances. Additionally, because of the potential reciprocal nature of these relationships, knowledge of how SUDs can have an impact on feelings of inferiority can assist practitioners in addressing and treating inferiority feelings through substance-use treatment and may encourage more Adlerians to practice in addiction treatment settings. Practitioners can work with clients on improving their sense of worth, competence, and inadequacy as a method of improving positive outcomes.

Finally, there are direct benefits to the study of Individual Psychology as a result of this research. Despite Adler's discussion of how substance addiction develops, current treatment modalities for 
SUDs do not heavily rely on Individual Psychology. Results of this study demonstrate that there is a place for Individual Psychology in addiction treatment, and empirical knowledge proving the relationship between Adlerian concepts and SUDs can assist in creating a stronger Individual Psychology presence in the treatment of SUDs.

Katie A. Lamberson, $\mathrm{PhD}$, LPC, CRC, is an assistant professor in the Counseling Department at the University of North Georgia, where she teaches in the clinical mental health and addictions track. Her research interests focus on family dynamics and substance use, and adolescent substance use, as well as issues around student-athlete mental health.

Kelly L. Wester, PhD, LPC, NCC, is a professor in the Department of Counseling and Educational Development at the University of North Carolina at Greensboro. Her research and clinical interests focus on the area of non-suicidal self-injury and other risk-taking behaviors, as well as research training and research integrity.

\section{References}

Abramson, Z. (2015). The meaning of neurosis according to Adler. Journal of Individual Psychology, 71(4), 426-439. https://doi.org/10.1353/jip.2015.0036

Adler, A. (1956). The Individual Psychology of Alfred Adler: A systematic presentation in selections from his writings (H. L. Ansbacher \& R. R. Ansbacher, Eds.). New York, NY: Harper \& Row.

Adler, A. (2005). Narcotic abuse and alcoholism. In H. T. Stein (Ed.), The collected clinical works of Alfred Adler (Vol. 7, pp. 50-59). Bellingham, WA: Classical Adlerian Translation Project.

Alexander, F. F. (1938). Remarks about the relation of inferiority feelings to guilt feelings. International Journal of Psychoanalysis, 19, 41-49.

Appel, H., Crusius, J., \& Gerlach, A. L. (2015). Social comparison, envy, and depression on Facebook: A study looking at the effects of high comparison standards on depressed individuals. Journal of Social and Clinical Psychology, 34(4), 277289. https://doi.org/10.1521/jscp.2015.34.4.277

Bandura, A. (1977). Social learning theory. Englewood-Cliffs, NJ: Prentice-Hall.

Barton-Bellessa, S. M., Lee, J., \& Shon, P. (2015). Correcting misconceptions about Alfred Adler's psychological theory of crime in introductory criminology textbooks: Moving Adler's theory of crime forward. Journal of Individual Psychology, 71(1), 3457. https://doi.org/10.1353/jip.2015.0006

Baumeister, R. F. (1998). The self. In D. Gilbert, S. Fiske, \& G. Lindzey (Eds.), The handbook of social psychology (pp. 680-740). New York, NY: Random House. 
Burleson, J. A., \& Kaminer, Y. (2005). Self-efficacy as a predictor of treatment outcome in adolescent substance use disorders. Addictive Behaviors, 30(9), 1751-

1764. https://doi.org/10.1016/j.addbeh.2005.07.006

Center for Behavioral Health Statistics and Quality. (2016). Key substance use and mental health indicators in the United States: Results from the 2015 National Survey on Drug Use and Health (HHS Publication No. SMA 16-4984, NSDUH Series No. H-51). Rockville, MD: Author. Retrieved from http://www.samhsa.gov/data/

Chen, G., Gully, S. M., \& Eden, D. (2001). Validation of a new general self-efficacy scale. Organizational Research Methods, 4(1), 62-83. https://doi.org/10.1177/109442810141004

Cook, D. R. (1988). Measuring shame: The Internalized Shame Scale. Alcoholism Treatment Quarterly, 4(2), 197-215.

Cook, D. R. (1996). Empirical studies of shame and guilt: The Internalized Shame Scale. In D. L. Nathanson (Ed.), Knowing feeling: Affect, script, and psychotherapy (pp. 132-165). New York, NY: Norton.

Coon, G. M., Pena, D., \& Illich, P. A. (1998). Self-efficacy and substance abuse: Assessment using a brief phone interview. Journal of Substance Abuse Treatment, 15(5), 385391. https://doi.org/10.1016/S0740-5472(97)00285-7

Davis, M., \& Vander Stoep, A. (1997). The transition to adulthood for youth who have serious emotional disturbance: Developmental transition and young adult outcomes. Journal of Mental Health Administration, 24(4), 400-427.

del Rosario, P. M., \& White, R. M. (2006). The Internalized Shame Scale: Temporal stability, internal consistency, and principal components analysis. Personality and Individual Differences, 41(1), 95-103. https://doi.org/10.1016/j.paid.2005.10.026

DiClemente, C. C., Carbonari, J. P., Montgomery, R. P. G., \& Hughes, S. O. (1994). The Alcohol Abstinence Self-Efficacy Scale. Journal of Studies on Alcohol, 55, 141-148.

Donnelly, J., Young, M., Pearson, R., Penhollow, T. M., \& Hernandez, A. (2008). Area specific self-esteem, values, and adolescent substance use. Journal of Drug Education, 38(4), 389403. https://doi.org/10.2190/DE.38.4.f

Dreikurs, R. (1990). Drug addiction and its individual psychological treatment. Individual Psychology, 46(2), 208-221.

Gausel, N., Leach, C., Vignoles, V. L., \& Brown, R. (2012). Defend or repair? Explaining responses to in-group moral failure by disentangling feelings of shame, rejection, and inferiority. Journal of Personality and Social Psychology, 102(5), 941960. https://doi.org/10.1037/a0027233 
Gupta, R. (1996). Inferiority feeling as a source of variation in adjustment of female adolescents. Journal of Personality and Clinical Studies, 12(1-2), 29-32.

Heatherton, T. F., \& Wyland, C. (2003) Assessing self-esteem. In S. Lopez and R. Snyder (Eds.), Assessing positive psychology (pp. 219-233). Washington, DC: APA.

Judge, T. A., Erez, A., \& Bono, J. E. (1998). The power of being positive: The relation between positive self-concept and job performance. Human Performance, 11, 167-187.

Kline, R. B. (2011). Principles and practice of structural equation modeling (3rd ed.). New York, NY: Guilford Press.

Marlatt, G. A. (1985). Relapse prevention: Theoretical rationale and overview of the model. In G. A. Marlatt \& J. R. Gordon (Eds.), Relapse prevention: Maintenance strategies in the treatment of addictive behaviors (pp. 3-70). New York, NY: Guilford Press.

McGaffin, B. J., Lyons, G. B., \& Deane, F. P. (2013). Self-forgiveness, shame, and guilt in recovery from drug and alcohol problems. Substance Abuse, 34(4), 396404. https://doi.org/10.1080/08897077.2013.781564

McKiernan, P., Cloud, R., Patterson, D. A., Golder, S., \& Besel, K. (2011). Development of a brief abstinence self-efficacy measure. Journal of Social Work Practice in the Addictions, 11(3), $245-253$.

Mosak, H., \& Maniacci, M. (1999). A primer of Adlerian psychology: The analytic-behavioralcognitive psychology of Alfred Adler. Philadelphia, PA: Brunner/Mazel Taylor \& Francis.

National Institute on Drug Abuse. (2014). Drugfacts: Nationwide trends. Retrieved from http://www.drugabuse.gov/publications/drugfacts/nationwide-trends

O’Connor, L. E., Berry, J. W., Inaba, D., Weiss, J., \& Morrison, A. (1994). Shame, guilt, and depression in men and women in recovery from addiction. Journal of Substance Abuse Treatment, 11(6), 503-510.

Pottick, K. J., Warner, L. A., Vander Stoep, A., \& Knight, N. M. (2014). Clinical characteristics and outpatient mental health service use of transition-age youth in the USA. Journal of Behavioral Health Services \& Research, 41(2), 230-243. https://doi.org/10.1007/s11414-013$\underline{9376-5}$

Rosenberg, M. (1965). Society and the adolescent self-image. Princeton, NJ: Princeton University Press.

Rybak, C., \& Brown, B. (1996). Assessment of internalized shame validity and reliability of the Internalized Shame Scale. Alcoholism Treatment Quarterly, 14, 1, 71-83. 
Scherbaum, C. A., Cohen-Charash, Y., \& Kern, M. J. (2006). Measuring general self-efficacy: A comparison of three measures using item response theory. Educational and Psychological Measurement, 66(6), 1047-1063. https://doi.org/10.1177/0013164406288171

Sherer, M., Maddux, J. E., Mercandante, B., Prentice-Dunn, S., Jacobs, B., \& Rogers, R. (1982). The Self-Efficacy Scale: Construction and validation. Psychological Reports, 53, 899-902.

Steffenhagen, R. A. (1974). Drug abuse and related phenomena: An Adlerian approach. Journal of Individual Psychology, 30(2), 238-250.

Strano, D. A., \& Dixon, P. N. (1990). The Comparative Feeling of Inferiority Index. Individual Psychology: Journal of Adlerian Theory, Research \& Practice, 46(1), 29-42.

Sweeney, T. J. (2009). Adlerian counseling and psychotherapy: A practitioner's approach. New York, NY: Routledge Taylor \& Francis Group.

Tangey, J. P. \& Dearing, R. L. (2002). Shame and guilt. New York, NY: Guilford Press.

Wiechelt, S. A. (2007). The specter of shame in substance misuse. Substance Use \& Misuse, 42(2-3), 399-409. https://doi.org/10.1080/10826080601142196 